\title{
Seepage Flow Model and Deformation Properties of Coastal Deep Foundation Pit under Tidal Influence
}

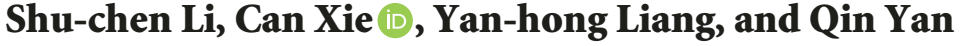 \\ Geotechnical and Structural Engineering Research Center, Shandong University, Shandong, China \\ Correspondence should be addressed to Can Xie; xiecansdu@163.com
}

Received 6 January 2018; Revised 12 February 2018; Accepted 11 March 2018; Published 16 April 2018

Academic Editor: Qin Yuming

Copyright (c) 2018 Shu-chen Li et al. This is an open access article distributed under the Creative Commons Attribution License, which permits unrestricted use, distribution, and reproduction in any medium, provided the original work is properly cited.

\begin{abstract}
As the coastal region is the most developed region in China, an increasing number of engineering projects are under construction in it in recent years. However, the quality of these projects is significantly affected by groundwater, which is influenced by tidal variations. Therefore, the regional groundwater dynamic characteristics under tidal impact and the spatiotemporal evolution of the seepage field must be considered in the construction of the projects. Then, Boussinesq function was introduced into the research to deduce the seepage equation under tidal influence for the coastal area. To determine the spatiotemporal evolution of the deep foundation pit seepage field and the coastal seepage field evolution model, numerical calculations based on changes in the tidal water level and seepage equation were performed using MATLAB. According to the developed model, the influence of the seepage field on the foundation pit supporting structure in the excavation process was analyzed through numerical simulations. The results of this research could be considered in design and engineering practice.
\end{abstract}

\section{Introduction}

Groundwater seepage significantly impacts the stability of foundation pit engineering and the deformation of the foundation pit support structure and, hence, is a major factor in several foundation pit engineering accidents [13]. Based on the generalized Darcy law, Atangana and Vermeulen [4] derived a new equation for groundwater flow and obtained an asymptotic analytical solution of the generalized groundwater flow equation by the Frobenius and Adomian decomposition method. And the feasibility of the solution was verified through comparisons with field test results. Finally, Atangana and Vermeulen further presented a proposition for reducing uncertainties in groundwater study. In order to investigate the influences of seepage field on mechanical property, Wang [5] developed a 3-Dimensional Stochastic Seepage finite element model and proposed a more comprehensive stochastic algorithm to analyze seepage field problems. Qiu et al. [6] established a statistical model and an artificial wavelet neural network model so as to improve predication accuracy.

To explore the impact of changes in seawater tides on variations in groundwater levels, Jacob [7] first established a one-dimensional tidal seepage equation. The equation could be used to fit the movement of seawater by using the sine trigonometric function or cosine trigonometric function. Jeng et al. [8] established a new groundwater seepage model by considering the dynamic effects of the phreatic aquifer on the head fluctuations in the confined aquifer and accordingly derived a closed-form analytical solution. In contrast to the previous solutions, the newly developed solution could describe the interaction effect between tidal oscillations and semiconfined/phreatic coastal aquifers. Li et al. [9] constructed a two-dimensional permeability model of coastal tides by using the boundary element method. They demonstrated that the groundwater amplitude decreased compared with the tide amplitude and the vibration phase was also deferred. Zhang et al. [10] considered the mechanical properties and seepage characteristics of aquifers to explore the interaction between the water level and seepage flow and to express the relationship between confined groundwater and tides using a mathematical equation. Numerous theories exist to describe the seepage of water. Guo [11] investigated a multilayer aquifer system comprising an upper weak permeable layer, a lower 
weak permeable layer, and a confined aquifer. According to the premise that the boundary between the sea and land is vertical, a mathematic model of groundwater level fluctuation with tides was established and an analytical solution was determined.

Numerous theories exist to describe the seepage of water. In particular, the Boussinesq equation has been widely employed [12-17]. Nielsen [12] analyzed the relationship between the inland average water table and tidal amplitude and solved the question of tidal dynamics on a sloping beach on the basis of the Boussinesq equation and a field monitoring test. A new Boussinesq equation was proposed and a set of formulae for groundwater recession was derived to use for groundwater flow in confined and unconfined aquifers [14]. Li et al. [15] presented a new method to improve the discontinuous boundary condition of the Boussinesq equation. The method is useful for handling the moving boundary condition by replacing the Boussinesq equation with an advection-diffusion equation with an oscillation velocity. Teo et al. [17] analyzed the effect of tidal fluctuation on the groundwater level and developed a new parameter to replace the factor of tilted shores.

It is suffice to note that foundation pit engineering in coastal areas and inland areas significantly differs in the influence of groundwater levels. In coastal areas, the groundwater level is directly affected by the tidal properties outside the pit. Because seepage characteristics may be different from the steady supply of the groundwater level, it is crucial to explore the seepage characteristics around a deep foundation pit under a tidal dynamic cycle. Therefore, this research proposes a seepage equation under tidal influence according to the Boussinesq function. To explore the deformation properties of the supporting structure in a deep foundation pit under tidal impact, a spatiotemporal evolution model of the seepage field was established in accordance with the onsite water level monitoring results of a deep foundation pit in a coastal area. In addition, a finite difference simulation software program was used to simulate the excavation process of the pit.

\section{Seepage Flow Model}

2.1. Seepage Equation. A side of a deep foundation pit near the coast was chosen because of its significant tidal impact. The following assumptions were made: (1) the seepage field has a gradually varied horizontal flow; (2) changes in the vertical seepage velocity are ignored because the vertical seepage velocity is much smaller than the horizontal seepage velocity; (3) the external precipitation recharge on the free surface is ignored. Because the tide level changes over time, the partial derivative with respect to time should be preserved in the study to explore the time-space evolution characteristics of the seepage field under tidal influence. It is supposed that the bottom bedrock of the pit is impermeable and no water-resisting layer exists among the backfill layers above the bedrock. The normal direction of the pit is the $x$ axis, the coastline is set as the origin of the $x$-axis, and the direction from the coastline to foundation pit is the positive

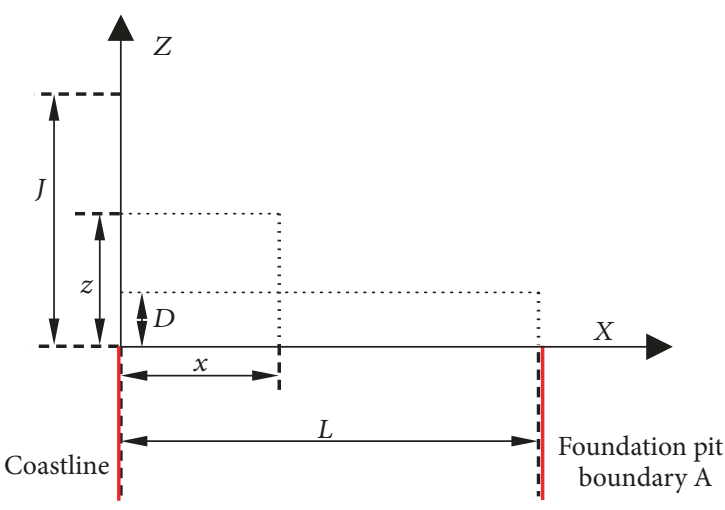

FIGURE 1: Diagrammatic drawing of seepage flow model.

direction of the $x$-axis. An unstable flow has been previously introduced [18-20]:

$$
\frac{\partial}{\partial x}\left[k Z(x, t) \frac{\partial Z(x, t)}{\partial t}\right]=\mu \frac{\partial Z(x, t)}{\partial t} .
$$

Here, $k$ is the permeability coefficient, $\mu$ is the gravitational specific yield and empirical value of $\mu$ is $0.23, t$ is the seepage time, $x$ is the seepage distance, and $Z(x, t)$ is a function of the seepage field free surface.

According to assumptions that (1) the distance from the foundation pit boundary to coastline is $L$ meters; (2) the function $f(t)$ is introduced to calculate the tide accords; and (3) $Z=0$ on the impermeable plane, as shown in Figure 1, since there are water-stop curtains around the foundation pit and the support structure is impermeable, the boundary condition at $x=L$ is obtained. That is, $\left.(\partial Z / \partial x)\right|_{x=L}=0$. Then, the boundary conditions of the seepage model can be expressed as follows:

$$
\begin{aligned}
& Z(0, t)=f(t) \\
& \left.\frac{\partial Z}{\partial x}\right|_{x=L}=0
\end{aligned}
$$

If the seepage flow is kept constant along the $x$-axis, the mean water levels of the seashore and foundation pit are $D$ and $J$, respectively. $z$ is the height of the phreatic line when $X=x$, as shown in Figure 1. The initial condition of the model could be derived according to the gradually varied seepage flow equation with a flat slope as follows [21, 22]:

$$
\begin{aligned}
q & =\frac{k}{2 L}\left(D^{2}-J^{2}\right)=\frac{k}{2 x}\left(D^{2}-z^{2}\right) \\
& =\frac{k}{2(L-x)}\left(z^{2}-J^{2}\right) .
\end{aligned}
$$

Here, $k$ is the permeability coefficient, $q$ represents the unit width flow, and $L$ is the distance between the coastline and foundation pit boundary. 
TABLE 1: Parameters of soil layer.

\begin{tabular}{|c|c|c|c|c|c|c|c|}
\hline Soil name & $\begin{array}{c}\text { Bulk } \\
\text { modulus/Mp }\end{array}$ & $\begin{array}{c}\text { Shear } \\
\text { modulus/Mp }\end{array}$ & Cohesion/Kpa & Friction $/^{\circ}$ & $\begin{array}{c}\text { Unit } \\
\text { weight/KN/m3 }\end{array}$ & $\begin{array}{c}\text { Permeability } \\
\text { coefficient } \mathrm{cm} / \mathrm{s}\end{array}$ & $\begin{array}{c}\text { Soil layer } \\
\text { thickness } / \mathrm{m}\end{array}$ \\
\hline Filling soil & 5.24 & 1.9 & 12.0 & 18 & 17.8 & $8.0 \times 10^{-5}$ & 3 \\
\hline Mucky soil & 2.16 & 0.89 & 19.6 & 15 & 18.4 & $2.0 \times 10^{-6}$ & 4 \\
\hline Silty clay & 19.8 & 10.3 & 20.7 & 25 & 20.2 & $6.0 \times 10^{-6}$ & 2 \\
\hline Gravel sand & 38.5 & 26.4 & 32.0 & 28 & 19.8 & $8.0 \times 10^{-2}$ & 2 \\
\hline Strongly weathered granite & 41000 & 31000 & 50.0 & 57 & 26.0 & $2.0 \times 10^{-10}$ & 30 \\
\hline
\end{tabular}

Therefore, the equation could be simplified to (4), and the initial condition could be expressed as (5).

$$
\begin{array}{r}
z=\sqrt{D^{2}-x \frac{D^{2}-J^{2}}{L}} \\
Z(x, 0)=\sqrt{D^{2}-x \frac{D^{2}-J^{2}}{L}} .
\end{array}
$$

Based on the above parameters, the seepage equation of the seepage field model could be given as follows:

$$
\begin{aligned}
\frac{\partial}{\partial x}\left[k Z(x, t) \frac{\partial Z(x, t)}{\partial x}\right] & =\mu \frac{\partial Z(x, t)}{\partial t} \\
Z(0, t) & =f(t) \\
\left.\frac{\partial Z}{\partial x}\right|_{x=l} & =0 \\
Z(x, 0) & =\sqrt{D^{2}-x \frac{D^{2}-J^{2}}{L}} .
\end{aligned}
$$

$$
\begin{array}{r}
Z(x, t)=f(t)+\sum_{n=1}^{\infty} C_{n} \sin \frac{(n+0.5) \pi x}{L} \cdot e^{\left((n+0.5)^{2} \pi^{2} / L^{2} p\right) t}+\int_{0}^{t} S(x, t: \iota) d \iota \\
\text { in which, } p=\frac{Z_{m} k}{u} ; C_{n}=\frac{2}{L} \int_{0}^{L} N(x) \cdot \sin \frac{(n+0.5) \pi x}{L} d x ; N(x)=e(x)-f(0) \\
S(x, t: \iota)=\sum_{n=1}^{\infty} A_{n} \sin \frac{(n+0.5) \pi x}{L} \cdot e^{\left((n+0.5)^{2} \pi^{2} / L^{2} p\right)(t-\iota)} ; \quad A_{n}=\frac{2}{L} \int_{0}^{L} M(x, \iota) \cdot \sin \frac{(n+0.5) \pi x}{L} d x ; M(x, \iota)=-f^{\prime}(\tau) .
\end{array}
$$

\section{Application to a Real Field Case: A Coastal Foundation Pit}

3.1. General Situation of a Coastal Foundation Pit. The coastal foundation pit chosen in the research is at $90 \mathrm{~m}$ from the bay. The field area mainly comprises Quaternary artificial fill and Holocene marine depositional strata. The physicomechanical parameters of every stratum are shown in Table 1. To support the foundation, a bored pile and an anchor cable support system is used in the engineering. The diameters of the bored pile and the waterproof pile are $800 \mathrm{~mm}$ while the pile spacing is $1200 \mathrm{~mm}$. The detailed profile of the support system is
2.2. Seepage Equation Solution. Several researchers have attempted to determine the solution of $(\partial / \partial x)[k Z(x, t)(\partial Z(x$, $t) / \partial t)]=\mu(\partial Z(x, t) / \partial t)[23,24]$. Therefore, the equation is linearized in this research. The first $Z(x, t)$ on the left side of the equation could be considered a constant and replaced with $Z_{m}\left(Z_{m}=(D+J) / 2\right)$. Accordingly, the linearized seepage equation is as follows:

$$
\begin{aligned}
Z_{m} k \frac{\partial^{2} Z}{\partial x^{2}} & =\mu \frac{\partial Z}{\partial t} \\
Z(0, t) & =f(t) \\
\left.\frac{\partial Z}{\partial x}\right|_{x=l} & =0 \\
Z(x, 0) & =e(x)
\end{aligned}
$$

Finally, the solution of the equation is again (see the Appendix for specific solutions)

$$
\text { in which, } e(x)=\sqrt{D^{2}-x \frac{D^{2}-J^{2}}{L}} \text {. }
$$

shown in Figure 2 and the parameters of the three anchor cables are indicated in Table 2.

According to the official hydrogeological data, the mean tide water level is $12.3 \mathrm{~m}(D=12.3 \mathrm{~m})$ and the average annual water level on the side of the foundation pit is $10.4 \mathrm{~m}(J=$ $10.4 \mathrm{~m}$ ). By analyzing the official hydrogeological data, the change of the tidal water level satisfies the following law:

$$
f(t)=1.2 * \sin \left(\frac{\pi t}{6}\right)+12.3
$$

The time-space evolution equation of the seepage field is obtained based on (8) and (9). The relationship of the 
TABLE 2: Calculated parameters of anchor.

\begin{tabular}{lcccccc}
\hline $\begin{array}{l}\text { Cable } \\
\text { number }\end{array}$ & $\begin{array}{c}\text { Horizontal } \\
\text { spacing/m }\end{array}$ & Angle $/^{\circ}$ & $\begin{array}{c}\text { Total length } \\
\text { of the } \\
\text { cables/m }\end{array}$ & $\begin{array}{c}\text { Length of free } \\
\text { segment/m }\end{array}$ & $\begin{array}{c}\text { Length of } \\
\text { anchorage/m }\end{array}$ & $\begin{array}{c}\text { Prestressing } \\
\text { locked } \\
\text { value/KN }\end{array}$ \\
\hline MG1 & 2.400 & 30 & 19.000 & 9.000 & 10.000 & 230 \\
MG2 & 2.400 & 25 & 20.000 & 10.000 & 10.000 & 290 \\
MG3 & 2.400 & 25 & 15.000 & 6.000 & 9.000 & 260 \\
\hline
\end{tabular}

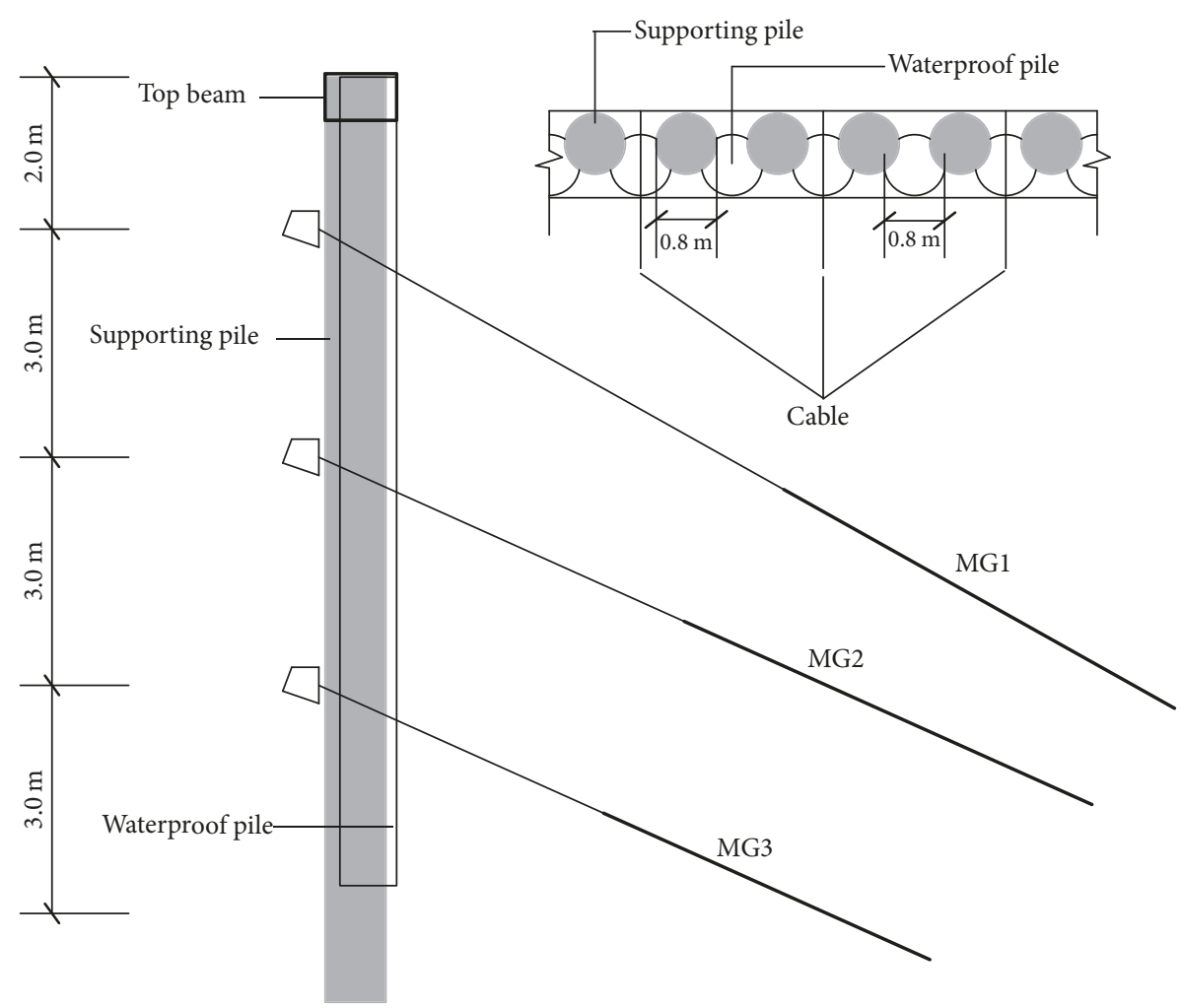

FIGURE 2: Cross-section of foundation pit supporting structure.

seepage field with time and infiltration distance is analyzed by MATLAB in two $24 \mathrm{~h}$ periods. The spatiotemporal evolutionary characteristic surface of the seepage field is presented in Figure 3.

3.2. Numerical Simulation. The FlAC ${ }^{3 \mathrm{D}}$ was used to analyze the stability of coastal deep foundation pit. The dimensions of the model established in the research are $80 \mathrm{~m} \times 50 \mathrm{~m} \times 40 \mathrm{~m}$ with an excavation depth of $11 \mathrm{~m}$ and an excavation width of $30 \mathrm{~m}$. The model is divided into 80000 zones and includes 8634 grid points. The mesh sketch of the numerical model is shown in Figure 4.

The upper surface of the model is a free boundary and the bottom surface of the model is a fixed boundary. The front and back boundaries constrain the displacement in the $y$ direction and the left and right boundaries constrain the displacement in the $x$ direction. The computation parameters of the soil and cable are given in Table 2. Based on the change in water level of the seepage path in a tidal cycle (as shown in Table 3), the pore water pressure was applied to the model as dynamic external stress. Then dynamic calculation was carried out during excavation of foundation pit. Figure 5 shows the calculation flow chart of numerical simulation.

\section{Analysis of Numerical Results}

Figure 6 shows that the change in the horizontal displacement of the model increases with the excavation depth. The maximum horizontal displacement occurs in the upper part of the foundation pit sidewall. The $X$-displacement of the model increases with the excavation depth of the foundation pit. The isosurface of the $X$-displacement is diffused in an arc and gradually tends to zero.

Figure 7 shows the surface subsidence around the foundation pit. It can be seen that the surface subsidence around the foundation pit gradually increases with the excavation depth and the maximum settlement is $10.5 \mathrm{~mm}$. The settlement mainly occurs near the top of the supporting structure. The maximum settlement emerges at the top of the pile with each excavation step. 


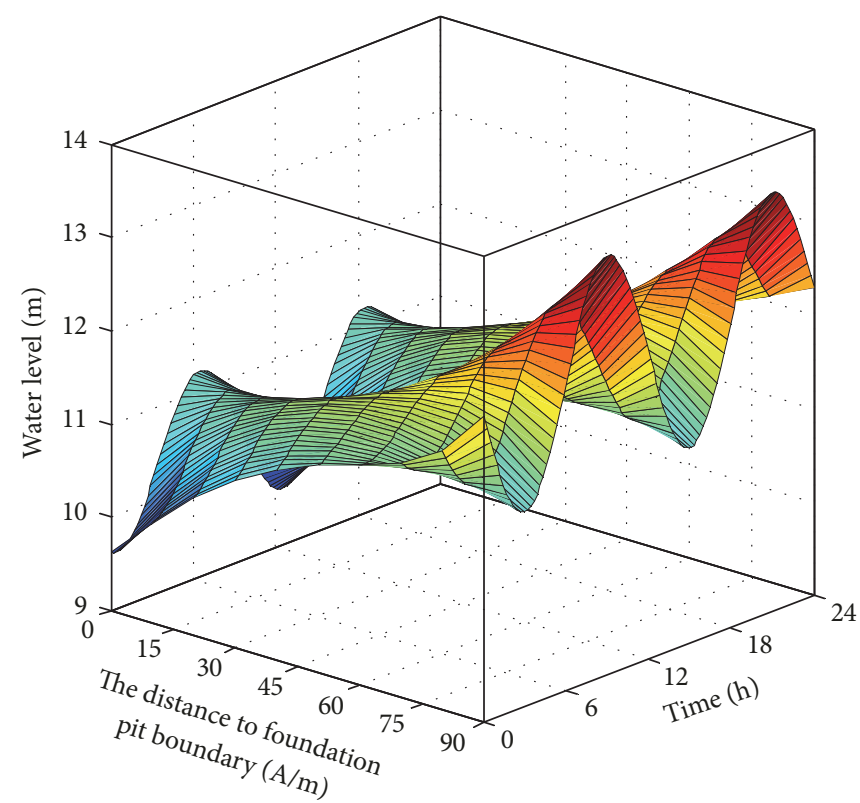

FIGURE 3: Three-dimensional image of spatiotemporal evolution characteristics of seepage.

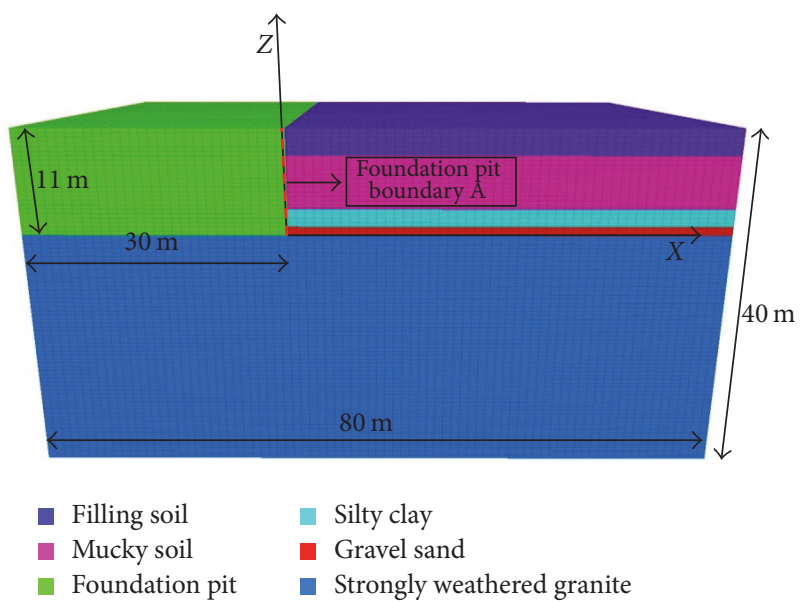

Figure 4: Mesh sketch of numerical model.

TABLE 3: Height of the water at different times in a cycle.

\begin{tabular}{|c|c|c|c|c|c|c|}
\hline \multirow{2}{*}{ Time/h } & \multicolumn{6}{|c|}{ The distance to foundation pit boundary $\mathrm{A} / \mathrm{m}$} \\
\hline & 0 & 10 & 20 & 30 & 40 & 50 \\
\hline 0 & 11.28401 & 11.49439 & 11.701 & 11.90401 & 12.10363 & 12.3 \\
\hline 1 & 11.27748 & 11.48821 & 11.70548 & 11.95825 & 12.31686 & 12.88317 \\
\hline 2 & 11.21904 & 11.50565 & 11.81959 & 12.20792 & 12.72075 & 13.39127 \\
\hline 3 & 11.26592 & 11.59036 & 11.97209 & 12.42218 & 12.93792 & 13.47478 \\
\hline 4 & 11.39505 & 11.71119 & 12.08309 & 12.48299 & 12.85621 & 13.10122 \\
\hline 5 & 11.5371 & 11.80319 & 12.09362 & 12.35372 & 12.50003 & 12.41591 \\
\hline 6 & 11.62077 & 11.81513 & 11.98634 & 12.075 & 12.00285 & 11.68551 \\
\hline 7 & 11.60111 & 11.73016 & 11.7924 & 11.74748 & 11.554 & 11.19419 \\
\hline 8 & 11.47615 & 11.57178 & 11.57891 & 11.49244 & 11.32484 & 11.13312 \\
\hline 9 & 11.28705 & 11.39417 & 11.42241 & 11.40428 & 11.40198 & 11.52606 \\
\hline 10 & 11.10159 & 11.26067 & 11.37873 & 11.51354 & 11.75339 & 12.22012 \\
\hline 11 & 10.98743 & 11.2187 & 11.46089 & 11.77477 & 12.2408 & 12.94526 \\
\hline 12 & 10.98548 & 11.28111 & 11.63385 & 12.08405 & 12.67334 & 13.41934 \\
\hline
\end{tabular}




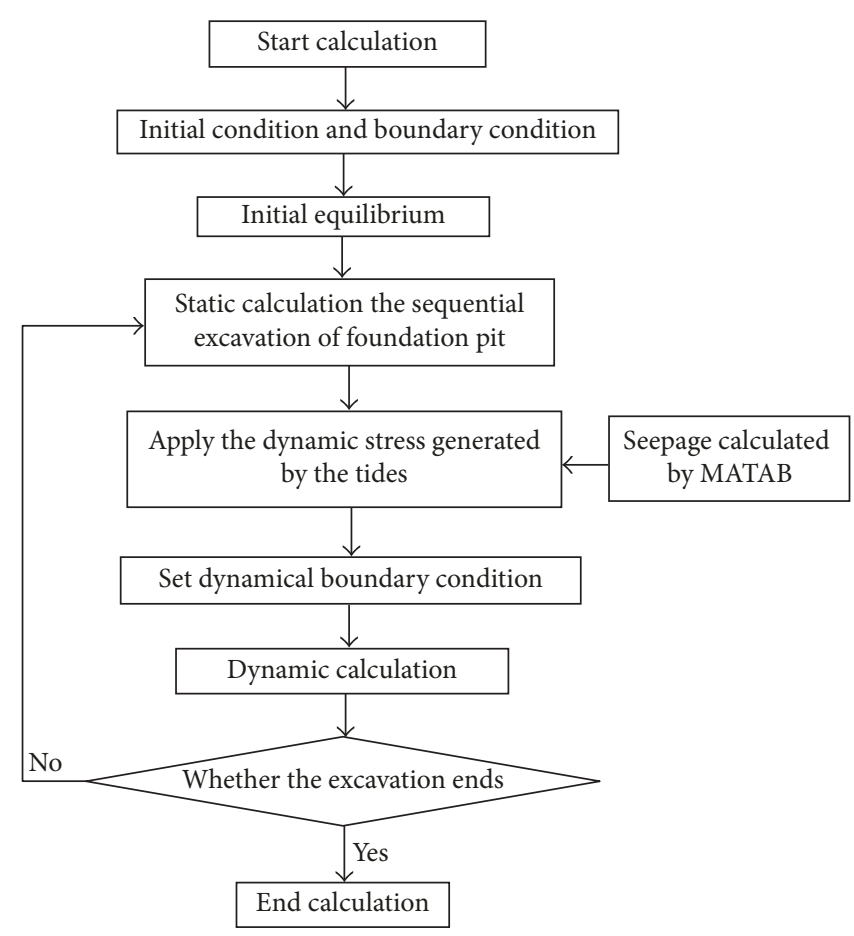

FIGURE 5: Calculation flow chart of numerical simulation.

Figures 8 and 9 show the results of horizontal and vertical displacements of the pile top at different excavation depth of deep foundation pit excavation. The simulation results of the horizontal and vertical displacements of the pile top are basically consistent with the site monitoring results. The horizontal and vertical displacements of the pile top affected by the tide are obviously increased compared with the displacements under anhydrous conditions. The deviation of the displacements increases with the excavation depth. The horizontal and vertical displacements of the pile top without tidal influence are $10.5 \mathrm{~mm}$ and $8.2 \mathrm{~mm}$ during excavation at the bottom of the foundation pit. However, the horizontal and vertical displacements of the pile top with tidal influence are $14.1 \mathrm{~mm}$ and $10.6 \mathrm{~mm}$, respectively. The increases are $34.3 \%$ and $22.6 \%$, respectively. It is shown that the bearing capacity and deformation of the supporting structure in the deep foundation pit are adversely affected by tides. Therefore, the tidal effect should be considered in the design of the support structure for a coastal deep foundation pit.

\section{Conclusions}

To solve the seepage mechanics problems of a foundation pit affected by tides, the equation of the seepage flow was deduced and the time-space evolution model of a seepage field for a deep foundation pit was established based on the Boussinesq function. The effects of time and space on seepage properties are considered sophisticated.

According to the results of in situ monitoring, the variations in the tide and groundwater level of the foundation pit on the ocean side were analyzed. Although the groundwater level of the foundation pit on the ocean side periodically changes, similar to the tide, the amplitude of the groundwater level is less than that of the tide. Based on the developed time-space seepage model, the dynamic water level of the coastal foundation pit seepage path was calculated by MATLAB and used to analyze the deformation of the support structure of the deep foundation pit under tidal influence. It is obviously seen that the seepage affected by tide has a significant influence on the deformation of the deep foundation pit and increases the security risk of engineering. Therefore, in order to ensure the safety of the foundation pit and improve the construction environment, the adverse effects of tides must be considered in the design and construction of deep foundation pits in coastal regions.

The dynamic and fluid coupling calculation is a rather complex question. We turned a complex problem into two relatively simple problems. One was simulated by MATLAB based on the seepage model presented in our manuscript and the other was simulated by dynamic calculation of FLAC ${ }^{3 \mathrm{D}}$. The study can provide a new idea for the stability analysis of deep foundation pit under the influence of tides.

\section{Appendix}

For

$$
\begin{aligned}
& Z_{m} k \frac{\partial^{2} Z}{\partial x^{2}}=u \frac{\partial Z}{\partial t} \\
& Z(0, t)=f(t) \\
& \left.\frac{\partial Z}{\partial x}\right|_{x=l}=0
\end{aligned}
$$




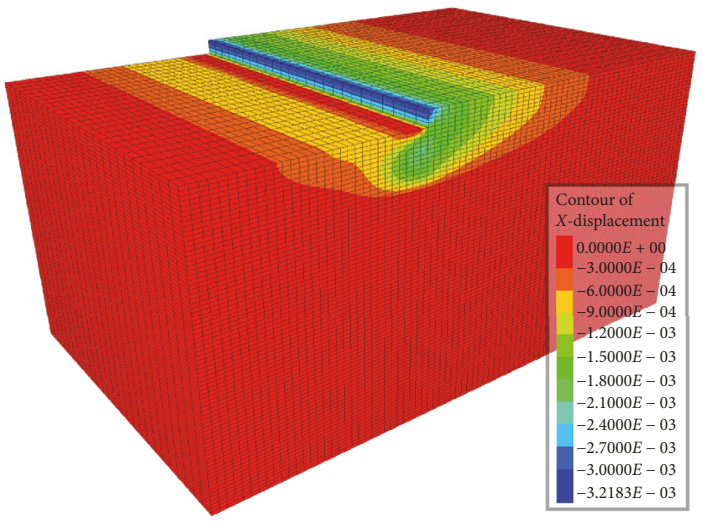

(a)

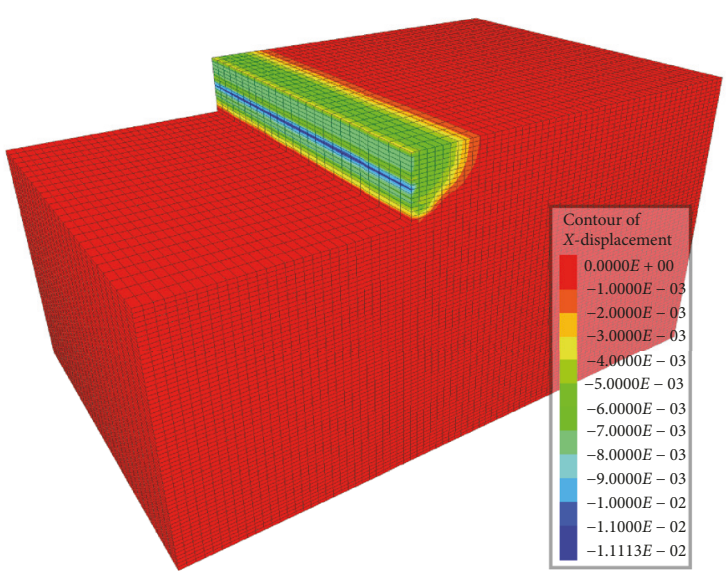

(c)

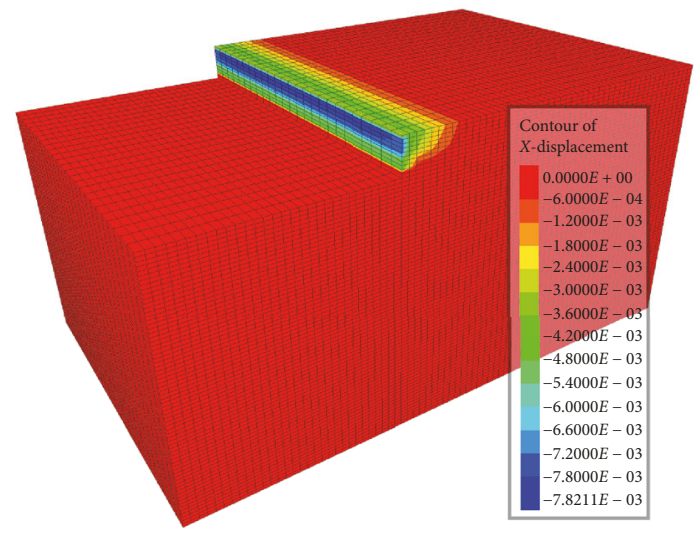

(b)

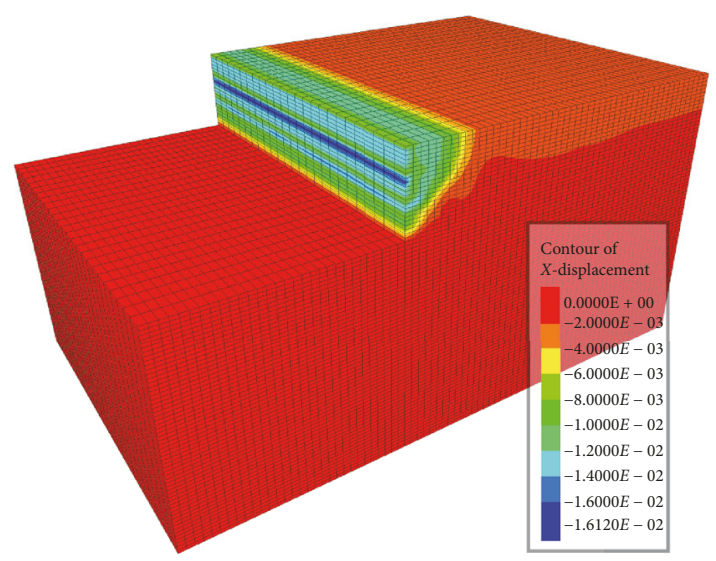

(d)

Figure 6: Contour of $X$-displacement.

$$
Z(x, 0)=e(x) \quad \text { in which, } e(x)=\sqrt{D^{2}-x \frac{D^{2}-J^{2}}{L}}
$$
assume that $V(x, t)=A(t) * x+B(t)$ satisfies (A.1); then

$$
V(x, t)=f(t)
$$

$$
\text { Assume that } Z(x, t)=V(x, t)+W(x, t) \text {. }
$$

The following equation will be obtained according to (A.1) and (A.2):

$$
\begin{aligned}
W_{t}-p W_{x x} & =-f^{\prime}(t) \\
W(0, t) & =0 \\
\left.\frac{\partial W}{\partial x}\right|_{x=L} & =0 \\
W(x, 0) & =N(x),
\end{aligned}
$$

where $p=u / Z_{m} k$ and $N(x)=e(x)-f(0)$.

$$
\text { Assume that } W(x, t)=W^{\mathrm{I}}(x, t)+W^{\mathrm{II}}(x, t) \text {. }
$$

Equation (A.5) is equivalent to the following equations:

$$
\begin{aligned}
W_{t}^{\mathrm{I}}-p W_{x x}^{\mathrm{I}} & =0 \\
W^{\mathrm{I}}(0, t) & =0 \\
\left.\frac{\partial W^{\mathrm{I}}}{\partial x}\right|_{x=L} & =0 \\
W^{\mathrm{I}}(x, 0) & =N(x) \\
W_{t}^{\mathrm{II}}-p W_{x x}^{\mathrm{II}} & =-f^{\prime}(t) \\
W^{\mathrm{II}}(0, t) & =0 \\
\left.\frac{\partial W^{\mathrm{II}}}{\partial x}\right|_{x=L} & =0 \\
W^{\mathrm{II}}(x, 0) & =0 .
\end{aligned}
$$




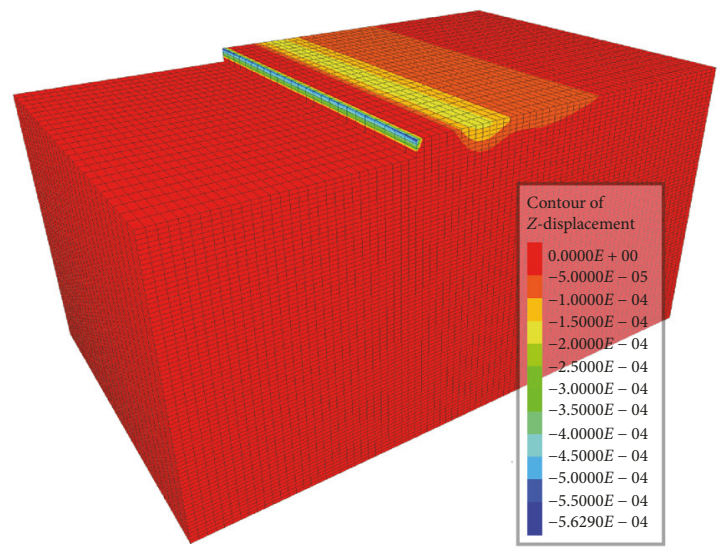

(a)

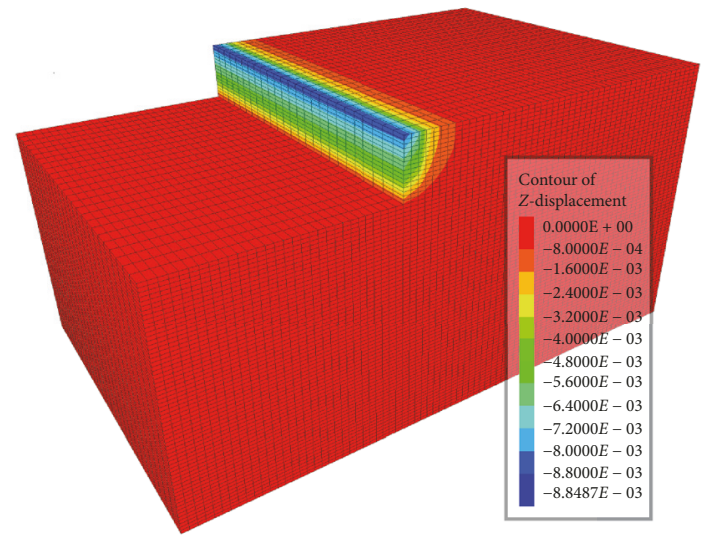

(c)

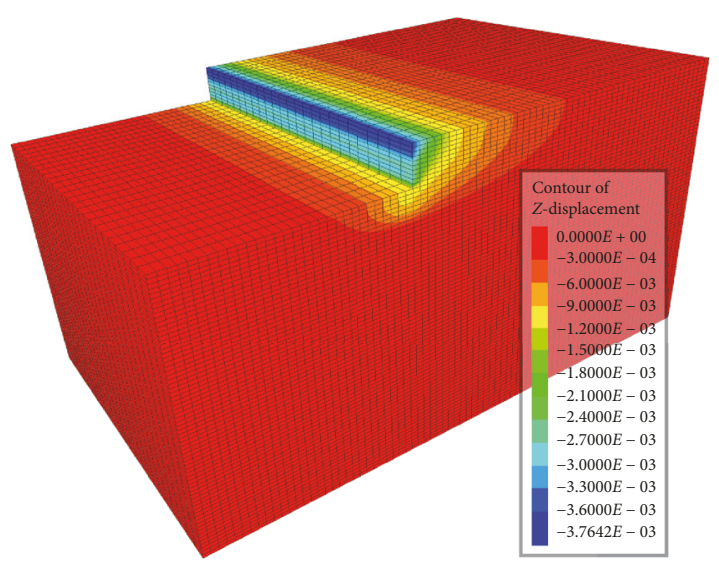

(b)

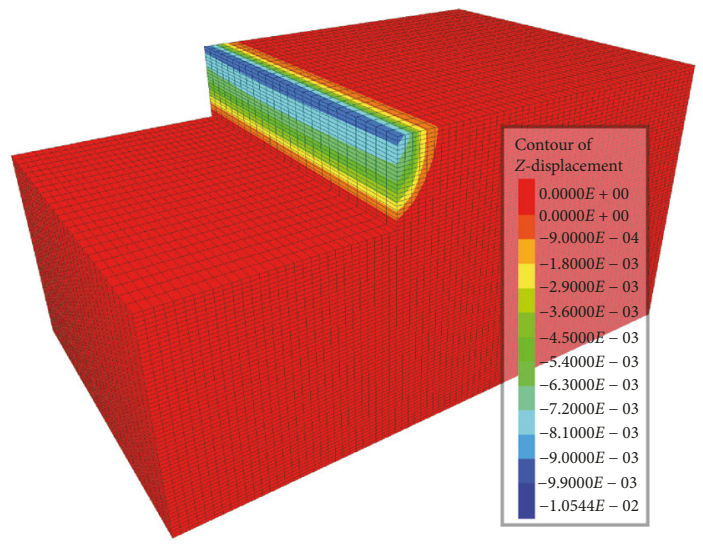

(d)

FIGURE 7: Surface subsidence around the foundation pit.

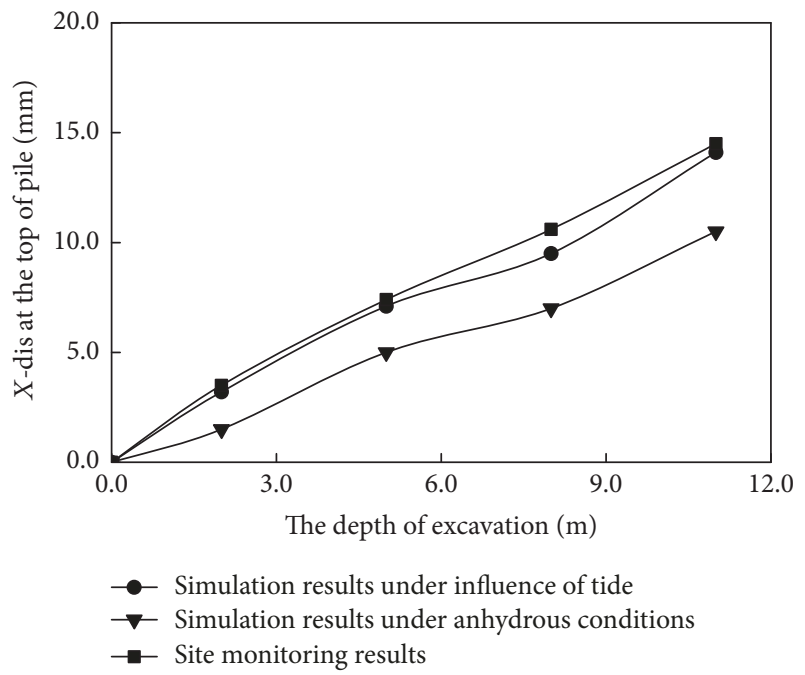

FIgURE 8: Horizontal displacement of pile top.

The solution of (A.6) was obtained by the method of separation of variables:

$$
W^{\mathrm{I}}(x, t)=\sum_{n=1}^{\infty} C_{n} \sin \frac{(n+0.5) \pi x}{L} \cdot e^{\left((n+0.5)^{2} \pi^{2} / L^{2} p\right) t}
$$

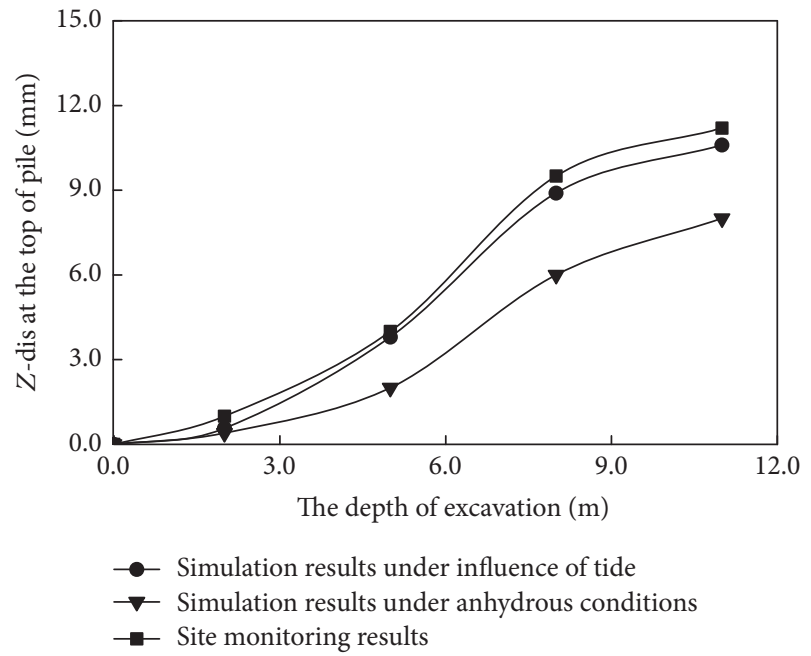

FIGURE 9: Vertical displacement of pile top.

Here, $C_{n}=(2 / L) \int_{0}^{L} N(x) \cdot \sin ((n+0.5) \pi x / L) d x ; N(x)=$ $e(x)-f(0)$.

For (A.7), based on theorem of impulse, the solution was adopted: 


$$
\text { Let } W^{\mathrm{II}}(x, t)=\int_{0}^{t} S(x, t: \iota) d \iota
$$

The following equations were obtained by combining (A.7) and (A.9):

$$
\begin{array}{r}
S_{t}-p S_{x x}=0 \\
S(0, t)=0
\end{array}
$$

$$
\begin{aligned}
& \left.\frac{\partial S}{\partial x}\right|_{x=L}=0 \\
& S(x, \tau)=-f^{\prime}(\tau) .
\end{aligned}
$$

The solution of (A.10) was also obtained by the method of separation of variables:

$$
S(x, t: \iota)=\sum_{n=1}^{\infty} A_{n} \sin \frac{(n+0.5) \pi x}{L} \cdot e^{\left((n+0.5)^{2} \pi^{2} / L^{2} p\right)(t-l)}
$$

$$
\text { In which, } A_{n}=\frac{2}{L} \int_{0}^{L} M(x, \iota) \cdot \sin \frac{(n+0.5) \pi x}{L} d x ; M(x, \iota)=-f^{\prime}(\tau) \text {. }
$$

Above all,

$$
\begin{array}{r}
Z(x, t)=f(t)+\sum_{n=1}^{\infty} C_{n} \sin \frac{(n+0.5) \pi x}{L} \cdot e^{\left((n+0.5)^{2} \pi^{2} / L^{2} p\right) t}+\int_{0}^{t} S(x, t: \iota) d \iota \\
\text { in which, } p=\frac{Z_{m} k}{u} ; C_{n}=\frac{2}{L} \int_{0}^{L} N(x) \cdot \sin \frac{(n+0.5) \pi x}{L} d x ; N(x)=e(x)-f(0) . \\
S(x, t: \iota)=\sum_{n=1}^{\infty} A_{n} \sin \frac{(n+0.5) \pi x}{L} \cdot e^{\left((n+0.5)^{2} \pi^{2} / L^{2} p\right)(t-\iota)} ; \quad A_{n}=\frac{2}{L} \int_{0}^{L} M(x, \iota) \cdot \sin \frac{(n+0.5) \pi x}{L} d x ; M(x, \iota)=-f^{\prime}(\tau)
\end{array}
$$

\section{Data Availability}

The data used to support the findings of this study are available from the corresponding author upon request.

\section{Conflicts of Interest}

The authors declare that there are no conflicts of interest regarding the publication of this paper.

\section{Acknowledgments}

The research work presented in this paper was supported by the National Natural Science Foundation of China (Grant no. 51379113) and the Specialized Research Fund of the National Key Research and Development Program of China (Grant no. 2016YFC0600803).

\section{References}

[1] J. Wang, X. Liu, Y. Wu et al., "Field experiment and numerical simulation of coupling non-Darcy flow caused by curtain and pumping well in foundation pit dewatering," Journal of Hydrology, vol. 549, pp. 277-293, 2017.

[2] A. Cong, "Discussion on several issues of seepage stability of deep foundation pit in multilayered formation," Chinese Journal of Rock Mechanics and Engineering, vol. 28, no. 10, pp. 20182023, 2009.

[3] N. Zhou, P. A. Vermeer, R. Lou, Y. Tang, and S. Jiang, "Numerical simulation of deep foundation pit dewatering and optimization of controlling land subsidence," Engineering Geology, vol. 114, no. 3-4, pp. 251-260, 2010.

[4] A. Atangana and P. D. Vermeulen, "Analytical solutions of a space-time fractional derivative of groundwater flow equation," Abstract and Applied Analysis, Article ID 381753, Art. ID 381753, 11 pages, 2014.

[5] Y. Wang, "3-Dimensional Stochastic Seepage Analysis of a Yangtze River Embankment," Mathematical Problems in Engineering, vol. 2015, Article ID 420264, 2015.

[6] J. Qiu, D. Zheng, and K. Zhu, "Seepage monitoring models study of earth-rock dams influenced by rainstorms," Mathematical Problems in Engineering, vol. 2016, Article ID 1656738, 11 pages, 2016.

[7] C. E. Jacob, Flow of ground water, John Wiley \& Son Inc, New York, NY, USA, 1950.

[8] D. S. Jeng, L. Li, and D. A. Barry, "Analytical solution for tidal propagation in a coupled semi-confined/phreatic coastal aquifer," Advances in Water Resources, vol. 25, no. 5, pp. 577584, 2002.

[9] L. Li, D. A. Barry, and C. B. Pattiaratchi, "Numerical modelling of tide-induced beach water table fluctuations," Coastal Engineering Journal, vol. 30, no. 1-2, pp. 105-123, 1997.

[10] D. S. Zhang, H. J. Zheng, and J. Geng, "Physical mechanism and unitary mathematical equation for tidal phenomena of ground 
water," Chinese Journal of Seismology and Geology, vol. 24, no. 2, pp. 208-214, 2002.

[11] Q. N. Guo, "Tide-induced groundwater fluctuation in a beach aquifer," Chinese Journal of Geotechnical Investigation \& Surveying, no. 5, pp. 36-39, 2010.

[12] P. Nielsen, "Tidal dynamics of the water table in beaches," Water Resources Research, vol. 26, no. 9, pp. 2127-2134, 1990.

[13] D. Liang, H. Gotoh, and A. Khayyer, "Boussinesq modelling of solitary wave and N-wave runup on coast," Applied Ocean Research, vol. 42, pp. 144-154, 2013.

[14] N. Su, "The fractional Boussinesq equation of groundwater flow and its applications," Journal of Hydrology, vol. 547, pp. 403-412, 2017.

[15] L. Li, D. A. Barry, F. Stagnitti, J.-Y. Parlange, and D.-S. Jeng, "Beach water table fluctuations due to spring-neap tides: Moving boundary effects," Advances in Water Resources, vol. 23, no. 8, pp. 817-824, 2000.

[16] H. Jiang, F. Liu, I. Turner, and K. Burrage, "Analytical solutions for the multi-term time-space Caputo-Riesz fractional advection-diffusion equations on a finite domain," Journal of Mathematical Analysis and Applications, vol. 389, no. 2, pp. 11171127, 2012.

[17] H. T. Teo, D. S. Jeng, B. R. Seymour, D. A. Barry, and L. Li, “A new analytical solution for water table fluctuations in coastal aquifers with sloping beaches," Advances in Water Resources, vol. 26, no. 12, pp. 1239-1247, 2003.

[18] J. Boussinesq, "Recherches théoriques sur l'écoulement des nappes d'eau infiltrées dans le sol et sur débit de sources," Journal De Mathématiques Pures Et Appliquées, vol. 10, no. 5, pp. 5-78, 1904.

[19] P. W. Werner, "Some problems in non-artesian ground-water flow, Eos, Transactions, American Geophysical Union, vol. 38, no. 4, pp. 511-518, 1957.

[20] B. H. Gilding, Mathematical modelling of saturated and unsaturated groundwater flow, World Scientific, Singapore, 1992.

[21] K. Sato and Y. Iwasa, Groundwater Hydraulics, Springer, Japan, 2000.

[22] A. M. Muir Wood, Coastal Hydraulics, Macmillan Education, London, UK, 1969.

[23] A. S. Telyakovskiy and M. B. Allen, "Polynomial approximate solutions to the Boussinesq equation," Advances in Water Resources, vol. 29, no. 12, pp. 1767-1779, 2006.

[24] A. S. Telyakovskiy, S. Kurita, and M. B. Allen, "Polynomialbased approximate solutions to the Boussinesq equation near a well," Advances in Water Resources, vol. 96, pp. 68-73, 2016. 


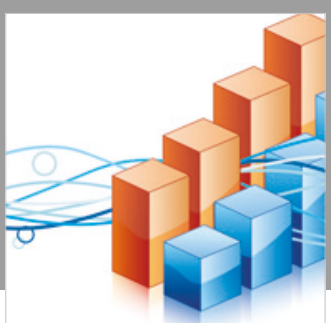

Advances in

Operations Research

\section{-n-m}
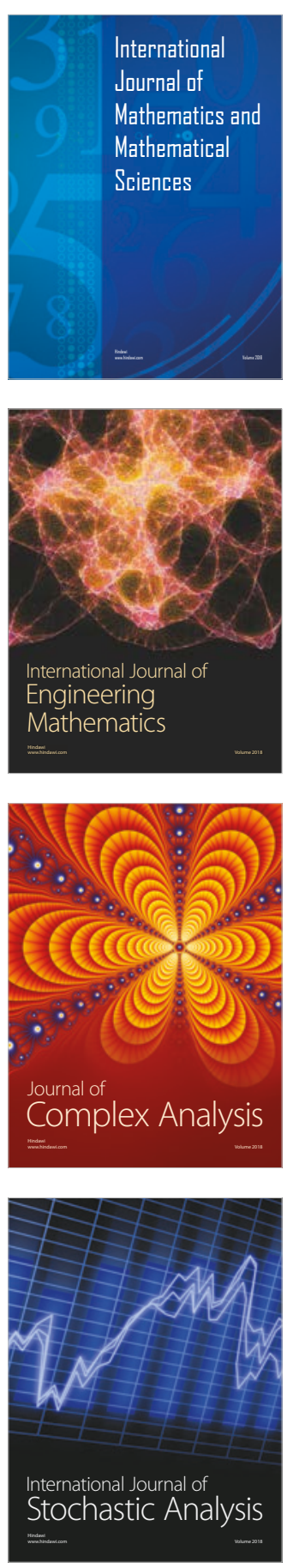
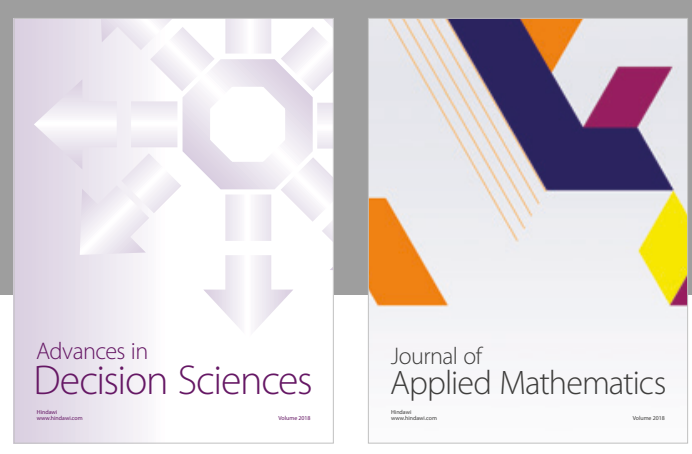

Journal of

Applied Mathematics
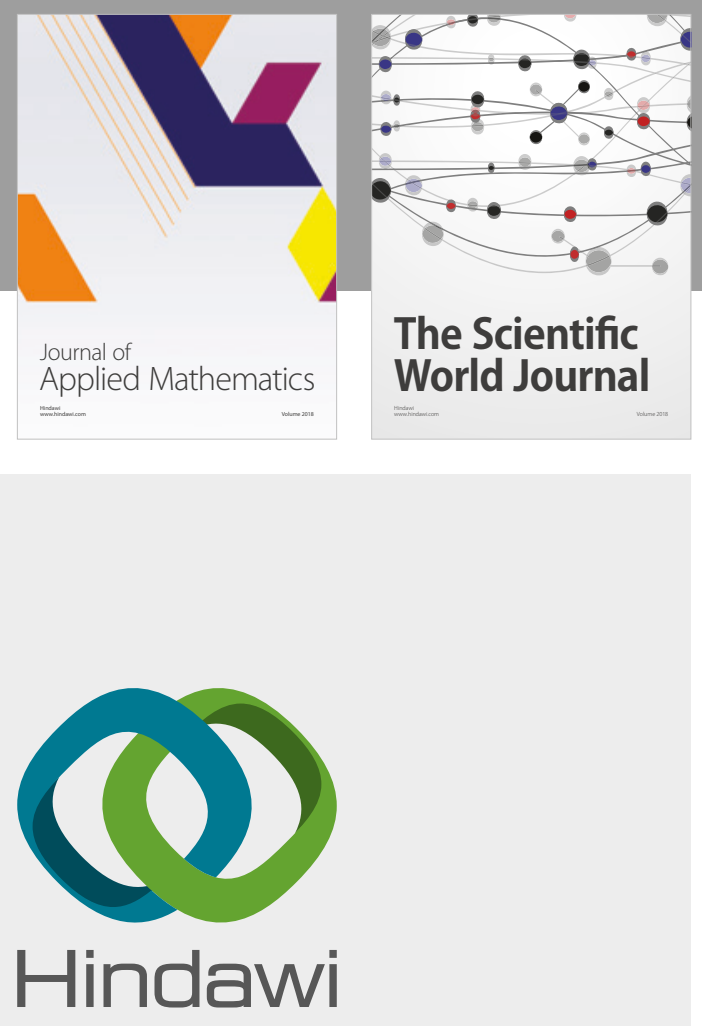

Submit your manuscripts at

www.hindawi.com

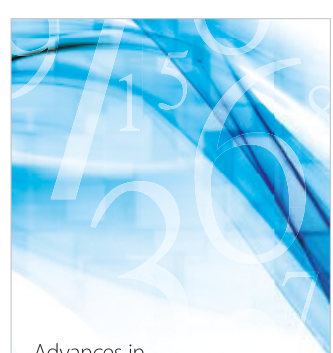

Advances in
Numerical Analysis
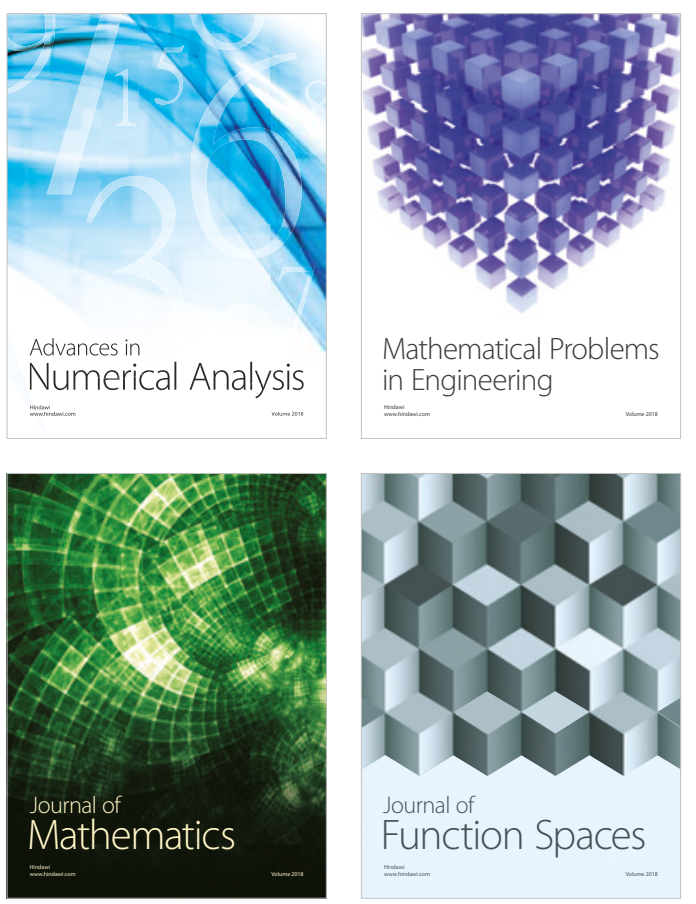

Mathematical Problems in Engineering

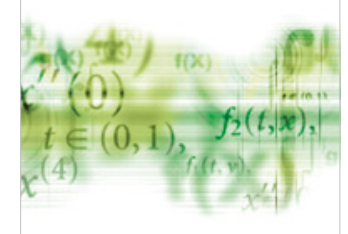

International Journal of

Differential Equations

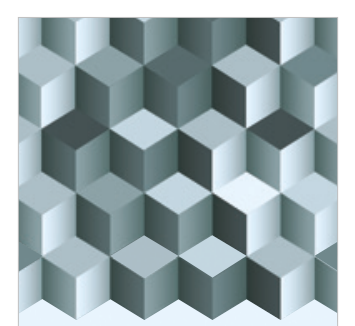

Journal of

Function Spaces

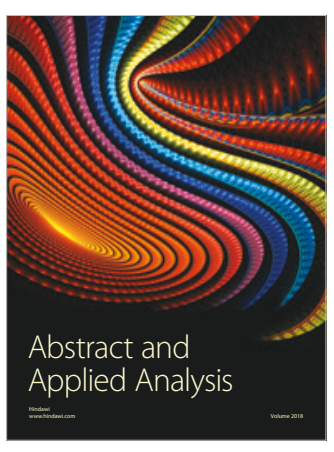

The Scientific

World Journal

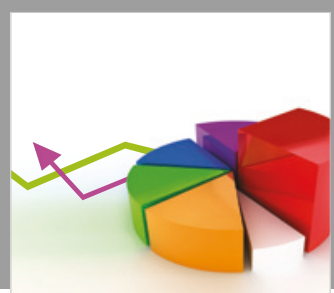

Journal of

Probability and Statistics
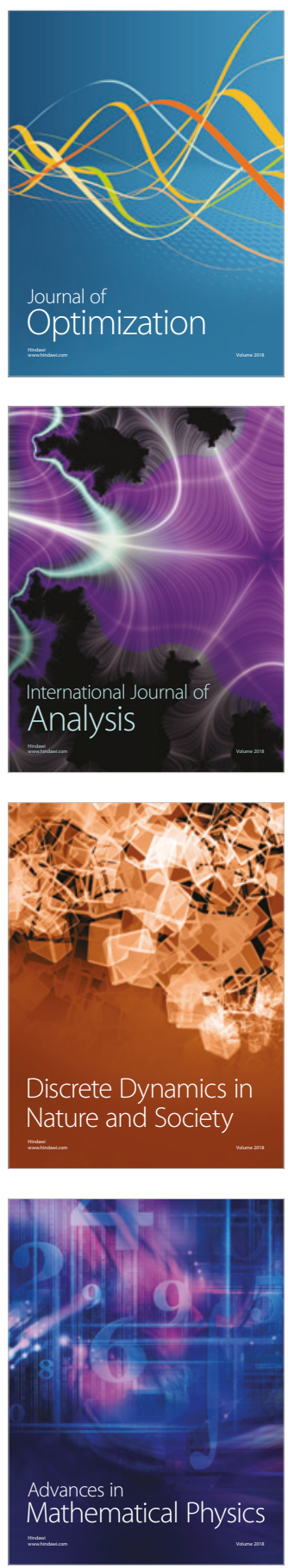